\title{
Políticas educacionais e a retomada da disciplina de Educação Moral e Cívica (EMC) no contexto atual
}

Educational policies and the resumption of the discipline of Moral and Civic Education (EMC) in the current context

\section{Políticas educacionales y la reintroducción de la asignatura de la Educación Moral y Cívica (EMC) en el contexto actual}

Maria Carolina Miesse ${ }^{1}$

Jani Alves da Silva Moreira ${ }^{1}$

Vânia de Fátima Matias de Souza ${ }^{1}$

doi: http://dx.doi.org/10.20435/serie-estudos.v0i0.1445

Resumo: O objetivo é analisar o processo de retorno da EMC na política educacional brasileira, fenômeno que se intensifica no contexto atual. Refere-se aos resultados de uma pesquisa exploratória, de análise crítica-contextualizada sobre a Lei n. 6.122/2018, que instituiu o retorno da EMC no currículo das redes pública e privada de ensino do Distrito Federal. Constata-se que o retorno da EMC no currículo propende a uma formação humana com bases antidemocráticas e moralizantes para o controle social.

Palavras-chave: Políticas Educacionais; Educação Moral e Cívica; Lei n. 6.122/2018.

Abstract: The objective is to analyze the process of return of EMC in the Brazilian educational policy, a phenomenon that is intensifying in the current context. It refers to the results of an exploratory research, of critical-contextualized analysis on Law n. 6.122/2018, which instituted the return of EMC in the curriculum of public and private educational networks of the Federal District. We noted that the return of EMC in the curriculum is prone to a human formation with anti-democratic and moralizing bases for social control.

Keywords: Educational Policies; Moral and Civic Education; Law n. 6.122/2018.

Resumen: El objetivo es analizar el proceso de regreso de la EMC en la política educacional brasileña, fenómeno que se intensifica en el contexto actual. Hace referencia a los resultados de una búsqueda exploratoria, de análisis crítica-contextualizada sobre la Ley n. 6.122/2018, que ha

1 Universidade Estadual de Maringá (UEM), Maringá, Paraná, Brasil. 
puesto el regreso de la EMC en el currículum de las redes pública y privada de la enseñanza del Distrito Federal. Se consta que el regreso de la EMC propende a una formación humana con bases antidemocráticas y moralizantes para el control social.

Palabras clave: Políticas Educacionales; Educación Moral y Cívica; Ley n. 6.122/2018.

\section{INTRODUÇÃO}

A disciplina de Educação Moral e Cívica (EMC) teve seu momento de maior intensidade na política curricular brasileira durante o período da Ditadura civil-militar, a partir do Decreto-Lei n. 869 (BRASIL, 1969), que a institucionalizou como disciplina obrigatória. Foi utilizada como meio de legitimação dos princípios conservadores e de organização política antidemocrática pautada em um intenso controle social moralizante no país.

Como disciplina obrigatória, a EMC foi disseminadora dos valores ideológicos da retórica liberalista que visava formar sujeitos coesos com o projeto de nação almejado pela elite do período ditatorial. Ela somente foi retirada do currículo no decorrer do período de redemocratização, após promulgação da Constituição de 1988, com a Lei n. 8.663 (BRASIL, 1993). Todavia, a partir dos anos 2000, verificou-se novamente a veiculação de propostas que preconizaram o retorno da EMC e, até os dias atuais, foram propostos 15 projetos de lei $(\mathrm{PL})$ e oito requerimentos de indicação (INC) na Câmara dos Deputados Federais, visando a sua inclusão na política curricular brasileira.

Causa inquietação o fato de que a veiculação dessas propostas obteve crescimento após o ano de 2015, quando se avistou a intensificação de forças reacionárias no país, sendo aprovada a Lei n. 6.122/2018 (BRASIL, 2018), que instituiu a EMC no currículo das redes pública e privada de ensino no Distrito Federal.

Diante da problemática anunciada, o presente texto, decorrente de uma pesquisa documental e exploratória, visa compreender o processo de retorno da EMC na política educacional brasileira. Para alcançar o proposto, em um primeiro momento apresentamos os antecedentes históricos da EMC, a fim de apreender a sua persistência na política curricular até 1993. Em seguida, analisamos o processo de veiculação de propostas na Câmara dos Deputados para sua reinserção a partir dos anos 2000, além da sua intensificação a partir de 2015. Por fim, analisamos as implicações da Lei n. 6.122/2018 (BRASIL, 2018), uma das proposições que foi implementada na política educacional atual, apesar de revogada no mesmo ano. 


\section{ANTECEDENTES HISTÓRICOS DA EMC E SUA PERSISTÊNCIA NA POLÍTICA CURRICULAR}

A EMC se faz presente dentro e fora das escolas desde o advento da República brasileira, "[...] com vistas à manipulação do imaginário popular [...]" (MELO, 2006, p. 21). A inserção da EMC objetivava tornar a República um regime aceito e venerado pela população, sendo empregada em alguns momentos de forma mais intensa, como no período do Estado Novo (1937-1945). Até mesmo em períodos menos autoritários, como na redemocratização pós-1945, esse conteúdo se fez presente nas práticas escolares. Percebe-se que a EMC foi utilizada com o intuito de consolidar um determinado poder político, uma prática intensificada principalmente pelos regimes ditatoriais (CUNHA; GÓES, 2002).

Um dos momentos de maior intensificação da EMC foi no período da Ditadura Civil-Militar (1964-1985), quando se instituiu a disciplina como obrigatória pelo Decreto-Lei n. 869, de 1969 (BRASIL, 1969), passando a integrar os currículos escolares de todos os graus e modalidades dos sistemas de ensino no país. A disciplina utilizava a escola como veículo de divulgação de valores ideológicos referentes à retórica liberalista, com intuito de promover a sociedade "coesa" e "pacífica" nos seus preceitos. Teria sido utilizada para formar o cidadão obediente aos valores sociais que o período de ditadura civil militar postulava, justamente para manter essa ordem social (JACOMELI, 2010).

Mesmo após o findar dessa organização política em 1985 e com os debates acerca da constituinte, estabelecida em 1988, a EMC permaneceu no currículo oficial como disciplina escolar e prática educativa em todos os níveis de ensino até 1993, ano em que, no governo de Itamar Franco (1992-1995), revogou-se o Decreto-Lei n. 869 (BRASIL, 1969) pela Lei n. 8.663 (BRASIL,1993). A partir do fim da década de 1970 e início da de 1980, a disciplina de EMC começou a ser questionada abertamente por associações científicas, como a Associação Nacional de História (Anpuh) e a Associação de Geógrafos do Brasil (AGB), e também pelos próprios professores de 1으 e 2 ㅇ grau (FILGUEIRAS, 2006).

Em 1985, "[...] diversas solicitações começavam a ser feitas ao CFE [Conselho Federal de Educação] para que a EMC fosse retirada dos currículos" (FILGUEIRAS, 2006, p. 183). Apesar disso e, até mesmo, de o CFE não discordar desse posicionamento, havia mais um empecilho ao findar da disciplina. "Em todos os relatórios o CFE afirmou que eles não tinham o poder de eliminar a EMC, pois sua 
obrigatoriedade foi estabelecida por um Decreto-Lei. Logo, somente poderia ser revogado por outra Lei ou Decreto-Lei elaborado por via legislativa" (FILGUEIRAS, 2006, p. 183-4).

Em uma busca no site da Câmara dos Deputados, identificou-se que, no ano de 1984, houve uma proposta para tornar facultativa, como disciplina e como prática educativa, a EMC, por meio do PL n. 3.199 (BRASIL, 1984), de José Eudes (PT/ RJ). O mesmo fora criticado pelo deputado Álvaro Valle (PFL/RJ), alegando, entre outras coisas, como registrado no diário do Congresso Nacional de 6 de junho de 1985, que o PL pretendia a eliminação de milhares de professores do magistério nacional, sob alegação de que esses "defendiam ideologias e governos" ao ensinar Sociologia, Ciência Política e História (BRASIL, 1985, p. 5.716).

Em 1986, ocorreu outra proposta para a extinção da obrigatoriedade da disciplina de EMC nos currículos escolares, o PL 7.449/1986 (BRASIL, 1986), de Aurélio Peres (PCDB/SP), que também não obtivera sucesso. No mesmo ano, a proposta de revogar o Decreto-Lei n. 869/69 (BRASIL, 1969) estava tramitando por intermédio da proposição do PL 7.445, de 17 de abril de 1986 (BRASIL, 1986), de autoria do próprio Poder Executivo, porém esse veio a se efetivar como a Lei n. 8.663, somente em 14 de junho de 1993 (BRASIL, 1993). Até mesmo no ano de 1991 foi realizada outra proposição com a mesma matéria legislativa, o PL 2.310/1991 (BRASIL, 1991), que não obtivera sucesso. Nesse ínterim, conseguimos averiguar que "[...] os preceitos considerados ideais na formação do cidadão perduraram para além do fim do Regime Militar" (GOMIDES, 2015, p. 146). Mediante o Art. 2ำ da Lei n. 8.663/1993, a carga horária das disciplinas de EMC, de Organização Social e Política do Brasil e dos Estudos dos Problemas Brasileiros deveria se incorporar sob critério das instituições de ensino e do sistema de ensino respectivo às disciplinas da área de Ciências Humanas e Sociais (BRASIL, 1993).

Apesar da revogação da EMC no currículo, suas ideias continuaram, visto que os valores por ela apresentados foram apropriados pela escola e, muitas vezes, expressos em práticas escolares (SANTOS, 2012). Práticas moralizantes nas escolas se perpetuaram, por meio do Ensino Religioso, que continuou como disciplina facultativa (NUNES, 2011). Tal disciplina se institucionalizava sem uma forma tão explícita de EMC, mas com viés religioso, uma vez que se constituiu enquanto conteúdo laico, entretanto, muitas vezes, esta característica não é contemplada nas práticas escolares. Na atualidade, os diversos projetos que tramitam no 
Congresso Nacional e que defendem a reintrodução da EMC no currículo possuem, predominantemente, uma defesa do conteúdo "religioso, explícito ou implícito, no texto do projeto e/ou na justificativa. A ética que faltaria no povo brasileiro é a defendida pelas religiões, especialmente as da vertente cristã" (CUNHA, 2019, p. 643). Portanto não é de se admirar a intensificação da defesa em projetos de leis para o retorno da EMC com vistas à formação cívica e moral do cidadão, como apresentaremos a seguir.

\section{FORMAÇÃO MORAL E CÍVICA DO CIDADÃO: PROPOSTA EM DISCUSSÃO}

Com o intento de verificar a retomada da EMC nos últimos anos, nas discussões legislativas, realizamos um levantamento na plataforma de busca de projetos de leis, no site eletrônico da Câmara dos Deputados, a partir do descritor "Educação Moral e Cívica" ${ }^{2}$. Identificamos, a partir do ano de 2000, propostas para reinserção desse conteúdo no currículo educacional brasileiro. Constatamos que, até o ano de 2019, foram propostos 15 projetos de lei (PL) e oito requerimentos de indicação (INC) sobre a inclusão da EMC na política curricular, tanto na forma de conteúdo transversal como de disciplina. Vale salientar que a constância da veiculação dessas propostas durante os anos fora intensificada a partir de 2015.

Percebemos que as propostas de reinserção da EMC de 2000 até 2012 estiveram presentes nas discussões legislativas, porém não em todos os anos. Já a partir de 2013 sua constância se intensificou. Desse momento, até 2019, foi apresentado ao menos um PL com essa matéria. Com base no levantamento de PLs e INCs sobre EMC, apresentamos na Figura 1 o gráfico que representa o quantitativo.

2 Levantamento realizado em jul. 2019. 
Figura 1 - Gráfico representativo da quantidade de projetos de lei e requerimentos de indicação sobre a volta da EMC de 2000 a 2019

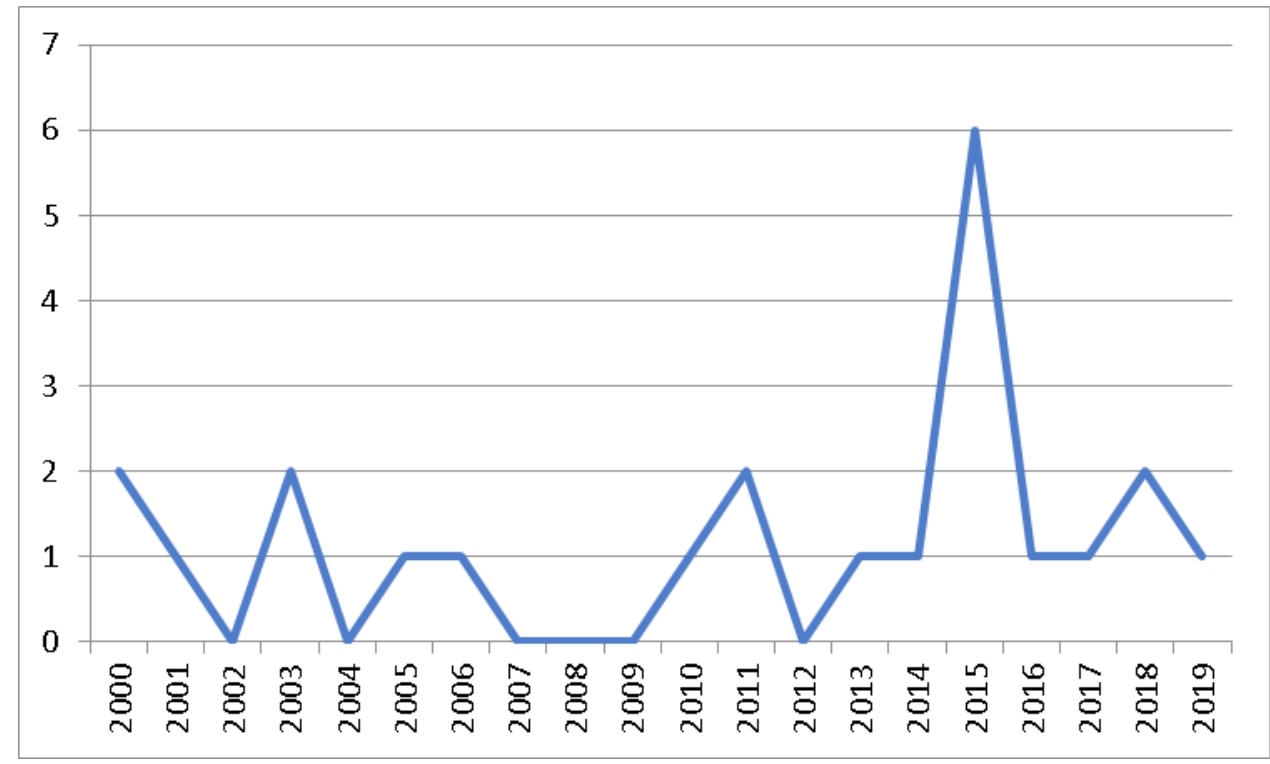

Fonte: Elaborado pela autora (2020) a partir da Câmara Federal: pesquisa simplificada (BRASIL, 2020).

Averiguamos por intermédio da representação acima que, a partir do ano de 2013, todos os anos dispõem de ao menos uma proposta de reinserção da EMC, porém, em 2015, houve um sobressalto no número de propostas, principalmente pela via do requerimento de indicação. Também, no ano de 2018, percebe-se que o quantitativo tem sido crescente.

Assinalamos que um dos fatores para essa prática educativa permanecer latente no período democrático brasileiro se pauta nas disputas curriculares que "têm como pano de fundo diferentes concepções de sociedade e de ordenamento socioeconômico" (ROSA, 2018, p. 51). De forma mais intensa, na atualidade, a nova direita neoliberal tem disputado os rumos da educação brasileira (FREITAS, 2018). Esse grupo defende uma educação que esteja de acordo com seus interesses de classe, já que ela é visualizada como instrumento para transformar as pessoas em cidadãos capazes de participar politicamente da sociedade democrática (SAVIANI, 2017). Busca-se formar pessoas que sigam as orientações que favoreçam os 
grupos hegemônicos, ou seja, que recebam uma instrução vinculada a uma ideia de unidade e coesão social (ALMEIDA, 2018).

A democracia da ordem capitalista refere-se a uma democracia burguesa que não propicia uma efetiva participação da população, principalmente a partir de 2016, em que houve uma intensificação dessa lógica evidenciada no processo de impeachment de Dilma Rousseff, considerada como "[...] incapaz de permanecer à frente dos interesses capitalistas que tanto serviu. Estes agora precisavam de um governo genuinamente burguês, capaz de não ceder o mínimo aos trabalhadores, de Ihes retirar o pouco que conquistaram [...]" (BRAZ, 2017, p. 87).

Tendo em vista que uma reflexão crítica sobre a realidade pode engendrar condições para uma formação de trabalhadores que participem da vida política da sociedade, como indica Freire (2015), é compreensível que esta seja cerceada em prol de interesses de classes, o que se intensifica em momentos de instabilidade política, em que distintas reformas curriculares são propostas com o objetivo de transmitir somente uma visão de mundo.

\section{EM DISCUSSÃO, A LEI N. 6.122/2018}

O cenário atual da política educacional brasileira conta com diversas proposições de retomada da EMC que, em sua maioria, de acordo com o site da Câmara dos Deputados Federais, são arquivadas e desarquivadas indistintas vezes. Também já há uma proposição aprovada acerca dessa matéria legislativa, mesmo que esta diga respeito somente ao Distrito Federal. Trata-se da Lei n. 6.122, de 1으 de março de 2018, que "Dispõe sobre a inclusão do tema educação moral e cívica como conteúdo transversal no currículo das redes pública e privada de ensino do Distrito Federal e dá outras providências" (BRASIL, 2018).

Nesse ínterim, questionamos o retorno da EMC e avistamos na análise da Lei n. 6.122/2018 um meio de compreendermos a lógica desse processo. Em um primeiro momento, destacamos os artigos 1 ㅇ e 2으 da Lei n. 6.122/2018, que estabelecem o seguinte:

Art. 1 o Fica incluído na grade curricular das escolas das redes pública e privada de educação infantil e ensino fundamental do Distrito Federal, como conteúdo transversal, o tema educação moral e cívica.

Art. 200 tema citado no art. 10 deve abordar princípios de moralidade e civilidade, devendo ser elaborado pelo setor técnico responsável da Secretária de Estado de Educação do Distrito Federal. (BRASIL, 2018, Art. 1ํe 2o). 
De acordo com a Lei n. 6.122/2018, o tema transversal de que trata deve abordar princípios de moralidade e civilidade. Quando comparamos esses princípios com os destacados nas finalidades da EMC presentes no Art. 2o do Decreto-Lei n. 869/1969, percebemos a retomada, principalmente, de dois de seus princípios, sendo eles:

[...] e) o aprimoramento do caráter, com apoio na moral, na dedicação à família e à comunidade; [...] g) o preparo do cidadão para o exercício das atividades cívicas com fundamento na moral, no patriotismo e na ação construtiva, visando ao bem comum [...]. (BRASIL, 1969, Art. 2, itens E e G, grifos nossos).

Podemos reafirmar o enfoque e a retomada dos princípios referidos, a partir do exposto na matéria intitulada Educação Moral e Cívica será incluída no currículo escolar, vinculada ao Informativo do Deputado Distrital Raimundo Ribeiro (INFORMATIVO..., 2018), concernente aos meses de janeiro e fevereiro de 2018. Neste, pontua-se qual seria o objetivo da Lei n. 6.122/2018 originada do PL 780/2015, de autoria do deputado Raimundo Ribeiro, e também quais seriam os seus ensinamentos. Na matéria, destaca-se que o retorno da EMC seria para "[...] o desenvolvimento e participação de crianças, jovens e adolescentes na sociedade. De maneira que contribuam para uma construção mais ética, com mais civilidade, do nosso país [...]" (INFORMATIVO..., 2018, p. 9). Seus ensinamentos específicos estariam então ligados a esse objetivo, pois, na visão dos defensores:

Atualmente, infelizmente, estamos diante de um quadro de valores destorcidos [sic]. Estamos deixando de lado a solidariedade, por exemplo. Isso, [sic] não pode continuar, temos que buscar soluções para frear. Precisamos, sim ensinar aqueles que serão o futuro do nosso país [...] (INFORMATIVO..., 2018, p. 9, grifos nossos).

Nesse cenário, os ensinamentos da EMC são numerados na matéria, sendo que se assemelham com os princípios destacados do Decreto-Lei n. 869/1969. Explicitamos essa relação no quadro a seguir, no qual comparamos ambos os enunciados: 
Quadro 1 - Comparação entre os princípios destacados no Decreto-Lei n. 869/1969 e os ensinamentos da EMC enumerados no Informativo do Deputado Distrital Raimundo Ribeiro

\begin{tabular}{|l|l|}
\hline \multicolumn{1}{|c|}{ Decreto-Lei n. 869/1969 } & $\begin{array}{l}\text { Ensinamentos da EMC enumerados } \\
\text { no Informativo do Deputado Distrital } \\
\text { Raimundo Ribeiro }\end{array}$ \\
\hline $\begin{array}{l}\text { "[...] e) o aprimoramento do caráter, com } \\
\text { apoio na moral, na dedicação à família e à } \\
\text { comunidade; [...] g) o preparo do cidadão } \\
\text { para o exercício das atividades cívicas com } \\
\text { fundamento na moral, no patriotismo e na } \\
\text { ação construtiva, visando ao bem comum } \\
\text { apoio moral, dedicação às famílias e } \\
\text { a...]" (BRASIL, 1969, Art. 2, itens E e G). }\end{array}$ & $\begin{array}{l}\text { das atividades cívicas, fundamento } \\
\text { moral no patriotismo e na ação } \\
\text { construtivas, sempre visando o bem" } \\
\text { (INFORMATIVO..., 2018, p. 9). }\end{array}$ \\
\hline
\end{tabular}

Fonte: Elaborado pela autora a partir do Decreto-Lei n. 869/1969 e do Informativo do Deputado Distrital Raimundo Ribeiro (INFORMATIVO..., 2018).

A essência da Lei n. 6.122/2018 (BRASIL, 2018) se apresenta no sentido de combater um quadro de valores distorcidos, entretanto preconiza ideias que foram tomadas por base na educação em um período antidemocrático. Nesse período histórico, as ideias presentes transmitiam às pessoas uma ideologia universal, neoliberal, de que aquela organização política "democrática" fora estabelecida para o bem de todos, assim era preciso valorizá-la cegamente, na defesa de que esse comportamento era o ser bom cidadão.

- Vale ressaltar que, além de retomar princípios antidemocráticos, a lei fora implementada de modo autoritário, sem um diálogo efetivo com os educadores, tanto de instituições públicas quanto privadas, como podemos ver em matéria do G1 do Distrito Federal, datada de 15/03/2018, dez dias após a publicação da Lei n. 6.122/2018. Além disso, conforme essa fonte, o PL n. 780/2015 que engendrou a lei fora vetado pelo governador Rodrigo Rollemberg (PSB), entretanto a decisão foi revertida pela Câmara Legislativa, sendo estabelecido que a temática fosse "[...] regulamentada em até 120 dias da data da sua publicação" (BRASÍLIA. 2018, Art. 6) e incluída "[...] na grade curricular após ratificação pelo Conselho de Educação do Distrito Federal” (BRASÍLIA. 2018, Art. 5ํ). A imposição dessa legislação recebeu críticas, tanto ao seu processo de tramitação quanto a suas características pedagógicas. 
O primeiro ponto de embate resultou na não instituição da EMC em Brasília, conforme matéria do G1, datada de 30/07/2019. Segundo a publicação, já em julho de 2018, quando a EMC deveria ser incluída, foi vetada pelo Conselho de Educação do DF com a justificativa de que a lei que a estabelecia era inconstitucional, na medida em que a Câmara Legislativa propunha um assunto que seria de alçada do Conselho de Educação do DF, conforme lei orgânica. Também, resultante de uma ação movida pelo Governo do Distrito Federal (GDF), a lei é declarada inconstitucional pelo Conselho Especial do Tribunal de Justiça do Distrito Federal e dos Territórios (TJDFT), por não ser declarada pelo GDF e por haver inadequações em sua forma, perdendo a validade no mês de julho de 2019.

O segundo ponto de discussão acerca da legislação em debate, como mostra a matéria do $\mathrm{G} 1$ de 15/03/2018, parte dos representantes de escolas particulares que consideraram a lei redundante, visto que a maioria das instituições de ensino aborda a temática cidadania em suas práticas, sendo parte de currículo oculto. Também a Secretaria de Educação de Brasília, responsável pelas escolas públicas, conforme essa fonte, recorreria à Justiça contra essa lei pelo mesmo motivo.

De fato, a própria Lei n. 9.394/1996, que estabelece as Diretrizes e Bases da Educação Nacional, quando define os princípios e fins da educação no Brasil, considera que esta "[...] tem por finalidade o pleno desenvolvimento do educando, seu preparo para o exercício da cidadania e sua qualificação para o trabalho" (BRASIL, 1996, Art. 2, grifos nossos). Quando a LDB trata das finalidades da educação básica, reforça essa questão, uma vez que estabelece que é de sua responsabilidade assegurar a seus educandos "[...] a formação comum indispensável para o exercício da cidadania [...] (BRASIL, 1996, Art. 22, grifos nossos).

Também no ano de 1997 verificou-se uma orientação condizente a essa temática nos Parâmetros Curriculares Nacionais (PCNs) quando, entre seus temas transversais, destaca a Ética. O documento salienta que o homem vive em sociedade, convivendo com outros homens, logo precisa questionar sobre como agir perante os outros sujeitos, questão central da ética e da moral, sendo estas referentes a "[...] um pensamento reflexivo sobre os valores e as normas que regem as condutas humanas" (BRASIL, 1997, p. 49).

Conforme o PCNs, não existem regras éticas/morais acabadas e estáticas. O que é considerado moral em determinada época pode ser considerado imoral em outra, a depender do contexto histórico-social. "A ética é um eterno pensar, 
refletir, construir. E a escola deve educar seus alunos para que possam tomar parte nessa construção, serem livres e autônomos para pensarem e julgarem" (BRASIL, 1997, p. 50). Assim, o documento salienta que sua proposta difere da EMC estabelecida em 1969, visto que esta impunha valores considerados corretos aos educandos, sem nenhum tipo de reflexão, como uma espécie de doutrinação.

Podemos perceber que a temática cidadania relacionada à Ética e Moral se faz presente nesse documento, entretanto definida "enquanto ação, prática, atitude e vivência [...]", não devendo ser engessada em "[...] uma disciplina, com conteúdos normativos, pré-estabelecidos" (FILGUEIRAS, 2006, p. 2, grifos nossos). Existe então um caráter de reflexão sobre as referidas temáticas, de modo que elas não se configurem com uma visão moralista.

Mas recentemente, com a implementação da Base Nacional Comum Curricular, também se percebe um enfoque na formação para a cidadania. Além de ser reforçada essa temática diversas vezes ao longo do texto, explicita-se também, entre as competências gerais da educação básica, a utilização dos conhecimentos para "[...] fazer escolhas alinhadas ao exercício da cidadania e ao seu projeto de vida, com liberdade, autonomia, consciência crítica e responsabilidade" (BRASIL, 2018, p. 9, grifos nossos). Um dos exemplos citados desse exercício da cidadania seria desenvolver no educando "[...] a condição de se inteirar dos fatos do mundo e opinar sobre eles, de poder propor pautas de discussão e soluções de problemas, como forma de vislumbrar formas de atuação na vida pública [...]" (BRASIL, 2018, p. 84).

Outros aparatos legais expressam questões relacionadas à formação cívica do estudante na política educacional. A partir do ano de 2009, pela Lei n. 12.031, definiu-se que, "Nos estabelecimentos públicos e privados de ensino fundamental, é obrigatória a execução do Hino Nacional uma vez por semana" (BRASIL, 2009, Art. 1ํ). Em 2011, temos, além da questão apresentada, a inclusão na LDB, pela Lei $n$. 12.472, do estudo sobre os símbolos nacionais como temática transversal nos currículos do ensino fundamental (BRASIL, 2011).

Com base nessas indagações e com o apresentado até o momento, podemos refletir que o surgimento da Lei n. 6.122/2018 esconde algumas intencionalidades. Não deve ser ao acaso que se intenta impor uma lei que torna obrigatória, como conteúdo transversal, a temática da formação cidadã, sendo que, na política educacional, já existem mecanismos que a efetivam. Visa-se a algum objetivo com 
a proposta, tendo em vista que ela demandaria esforços para sua aplicabilidade. Também não podemos deixar de lado que essa lei pretendia retomar o referido assunto, entretanto com a nomenclatura "Educação Moral e Cívica". Como visto anteriormente, esta é prescrita com mais intensidade no momento da Ditadura civil-militar, quando se efetivou enquanto disciplina que almejava formar cidadãos para atuar naquela ordem antidemocrática.

Essa política caracteriza-se como um instrumento para disseminar à população as ideias neoliberais do período, moralizando os educandos em uma visão concisa de mundo em concomitância com os ideais das frações da classe dominante. Desse modo, freia-se o acesso a uma visão crítica de sociedade, não permitindo que os cidadãos compreendam as injustiças de que são vítimas para manter a hegemonia econômica de certos grupos, lógica própria de contextos pós-golpes políticos, que muitas vezes cerceiam até mesmo direitos já conquistados pela classe trabalhadora. Intentam instituir um comportamento patriota, um cidadão que sirva a sua pátria cegamente, sem ter clareza de que reproduz as ideias dominantes que "[...] são a expressão das relações que fazem de uma classe a classe dominante, são as ideias de sua dominação" (MARX; ENGELS, 2007, p. 47).

Por fim, avista-se que a formação cidadã vinculada por meio da EMC serve a objetivos específicos, não relacionados a uma reflexão crítica do que seja a prática da cidadania, mas sim à instituição de uma ideia de civismo alienante, moralizador e perseguidor de pensamentos contrários aos hegemônicos, servindo, assim, a antidemocracia. Não por mera coincidência, essa questão da educação cívica vem sendo retomada em ampla escala por meio da institucionalização de um programa nacional de escolas cívico-militares que enfatizam a formação cívica do cidadão (BRASIL, 2019).

\section{CONSIDERAÇÕES FINAIS}

A EMC, instituída como disciplina na Ditadura civil-militar, permaneceu nos currículos escolares até o ano 1993, quando se revogou o Decreto-Lei n. 869/1969. Apesar do contexto de abertura democrática, a revogação da disciplina fora criticada por legisladores e, mesmo após sua retirada do currículo, suas práticas escolares não desapareceram completamente. Também a partir do ano 2000, após sete anos de retirada da EMC dos currículos escolares, constatam-se propostas para sua reinserção na política educacional brasileira. 
As propostas educativas advindas dos setores mais conservadores vislumbram precaver as ameaças que a democracia burguesa enfrenta ao longo do tempo, a partir da pequena brecha de participação política. Assim, é preciso cercear a voz dessas forças antagônicas, não ofertando à população meios que possam prover sua criticidade quanto a sua posição de explorados.

A EMC serviu aos objetivos citados, principalmente em seu período de maior intensidade no momento da Ditadura Civil-Militar, logo, poderia novamente ser utilizada para esses. Confirmamos essa afirmação tendo em vista que, em um momento de crise política, essas propostas ampliaram significativamente, inclusive sendo aprovada a Lei n. 6.122/2018 (BRASIL, 2018), mesmo que tenha perdurado por pouco tempo.

No Informativo do Deputado Distrital Raimundo Ribeiro, propositor do Projeto de Lei n. 780/2015, que engendrou a Lei n. 6.122/2018, observamos que as categorias discursivas defendidas na EMC no período ditatorial são retomadas como justificativa para sua reinserção no currículo. Tendo em vista esse fato e a reorganização histórica/política brasileira nos últimos anos, visualizamos que o retorno da EMC no currículo caracteriza-se como um instrumento de disseminação das ideias neoliberais que propendem à moralização dos sujeitos, por meio de uma visão concisa de mundo em concomitância com os ideais da classe dominante reacionária.

Por fim, acreditamos que a reflexão sobre a cidadania e atuação dos alunos na sociedade e no espaço geográfico em que vivem deve se efetivar não com um aspecto moralizante e universal, mas sim como prática de ação e reflexão realizada a partir dos conhecimentos produzidos historicamente pela humanidade e de forma não isolada. Defendemos que a escola seja o lugar em que as pessoas tenham contato com um pluralismo de ideias e concepções de mundo, de modo a agirem conscientes e não subservientes às demandas impostas pelo capital.

\section{REFERÊNCIAS}

ALMEIDA, Silvio Luiz. Neoconservadorismo e liberalismo. In: GALLEGO, Esther Solano (Org.). O ódio como política: a reinvenção das direitas no Brasil. 1. ed. São Paulo: Boitempo, 2018. p. 27-32.

AULA DE MORAL E CÍVICA em escolas do DF é inconstitucional, decide justiça. G1 - Distrito Federal, Brasília-DF, 30 jul. 2019. 
BRASIL. Pesquisa simplificada. Portal Câmara dos Deputados, 2020. Disponível em https:// www.camara.leg.br/buscaProposicoesWeb/pesquisaSimplificada. Acesso em: 10 jan. 2020.

BRASIL. Decreto n. 10.004, de 5 de setembro de 2019. Institui o Programa Nacional das Escolas Cívico-Militares. Brasília-DF, 2019.

BRASIL. Lei n. 6.122, de 5 de março de 2018. Dispõe sobre a inclusão do tema educação moral e cívica como conteúdo transversal no currículo das redes pública e privada de ensino do Distrito Federal. Brasília-DF, 2018. Disponível em: http://www.normasbrasil. com.br/norma/lei-6122-2018-df_357468.html. Acesso em: 4 jun. 2018.

BRASIL. Base Nacional Comum Curricular (BNCC). Educação é a Base. Brasília: MEC/ CONSED/UNDIME, 2018. Disponível em: http://basenacionalcomum.mec.gov.br/images/ BNCC_El_EF_110518_versaofinal_site.pdf. Acesso em: 2 nov. 2019.

BRASIL. Lei n. 12.472, de 10 de setembro de 2011. Acrescenta $\S 60$ ao art. 32 da Lei no 9.394, de 20 de dezembro de 1996, que estabelece as diretrizes e bases da educação nacional, incluindo os símbolos nacionais como tema transversal nos currículos do ensino fundamental. Brasília-DF, 2011.

BRASIL. Lei n. 12.031, de 21 de setembro de 2009. Altera a Lei n. 5.700, de $1^{\circ}$ de setembro de 1971, para determinar a obrigatoriedade de execução semanal do Hino Nacional nos estabelecimentos de ensino fundamental. Brasília-DF,2009.

BRASIL. Ministério da Educação e do Desporto. Secretaria de Educação Fundamental. Parâmetros curriculares nacionais: apresentação dos temas transversais, ética. Brasília: MEC/SEF, 1997.

BRASIL. Ministério de Educação e Cultura. Lei n. 9.394/96, de 20 de dezembro de 1996. Estabelece as diretrizes e bases da Educação Nacional. Brasília: MEC, 1996.

BRASIL. Lei n. 8.663, de 14 de junho de 1993. Revoga o Decreto-Lei n. 869, de 12 de dezembro de 1969, e dá outras providências. Brasília-DF, 1993.

BRASIL. Projeto de lei n. 2.310, de 27 de novembro de 1991. Revoga o decreto-lei 869, de 12 de setembro de 1969, e dá outras providências. Brasília, DF: Câmara dos Deputados, 1991.

BRASIL. Projeto de lei n. 7.445, de 17 de abril de 1986. Extingue a Comissão Nacional de Moral e Civismo e dá outras providências. Brasília-DF: Câmara dos Deputados. 1986a. 
BRASIL. Projeto de lei n. 7.449, de 17 de abril de 1986. Extingue a obrigatoriedade da disciplina "Educação Moral e Cívica" nos currículos escolares, altera dispositivos da Lei n. 5.692, de 11 de agosto de 1971, que fixa diretrizes e bases para o ensino de primeiro e segundo graus, e dá outras providências. Brasília-DF: Câmara dos Deputados, 1986b.

BRASIL. Diário do Congresso Nacional, de 6 de junho de 1985, ano XL, n. 61.

BRASIL. Projeto de lei n. 3.199, de 28 de março de 1984. Torna facultativa, como disciplina e como prática educativa, a Educação Moral e Cívica, nas escolas de todos os graus e modalidades, dos sistemas de ensino do país. Brasília-DF: Câmara dos Deputados, 1984.

BRASIL. Decreto-lei n. 869, de 12 de setembro de 1969. Dispõe sobre a inclusão da Educação Moral e Cívica como disciplina obrigatória, nas escolas de todos os graus e modalidades, dos sistemas de ensino no País, e dá outras providências. Brasília-DF, 1969.

BRAZ, Marcelo. O golpe nas ilusões democráticas e a ascensão do conservadorismo reacionário. Serviço Social e Sociedade, São Paulo, n. 128, p. 85-103, jan./abr. 2017.

CUNHA, Luiz Antônio. A educação moral, cívica e física. In: CUNHA, Luiz Antônio; GÓES, Moacyr. O golpe na educação. 11. ed. Rio de Janeiro: Jorge Zahar, 2002. p. 71-87.

CUNHA, Luiz Antônio. Religião, moral e civismo em curso: a marcha da socialização política. Revista Retratos da Escola, Brasília, v. 13, n. 27, p. 637-54, set./dez. 2019.

ESCOLAS DO DF questionam lei que institui Educação Moral e Cívica. G1 - Distrito Federal, Brasília, 15 mar. 2018.

FILGUEIRAS, Juliana Miranda. A Educação Moral e Cívica e sua produção didática: 19691993. 2006. Dissertação (Mestrado em Educação: História, Política, Sociedade) - Pontifícia Universidade Católica de São Paulo, São Paulo, SP, 2006.

FREIRE, Paulo. Educação como prática da liberdade. Rio de Janeiro: Paz e Terra, 2015.

FREITAS, Luiz Carlos. Origens e fundamentos da reforma: breve contextualização. In: FREITAS, Luiz Carlos. A reforma empresarial da educação. 1. ed. São Paulo: Expressão popular, 2018. p. 13-30.

GOMIDES, Fernanda de Paula. Representações de cidadania nos livros didáticos de Educação Moral e Cívica durante o regime militar brasileiro (1964-1985). 2015. Dissertação (Mestrado em Educação) - Centro de Educação (CE) da Universidade Federal da Paraíba, João Pessoa, PB, 2015. 
JACOMELI, Mara Regina Martins. A lei n. 5.692 de 1971 e a presença dos preceitos liberais e Escolanovistas: os estudos sociais e a formação da cidadania. Revista HISTEDBR on-line, Campinas, n. 39, p. 76-90, set. 2010.

MARX, Karl; ENGELS, Friedrich. Karl Marx Friedrich Engels - Feuerbach e história. In: MARX, Karl; ENGELS, Friedrich. A ideologia alemã: crítica da mais recente filosofia alemã em seus representantes Feuerbach, B. Bauer e Stirner, e do socialismo alemão em seus diferentes profetas (1845-1846). Tradução de Rubens Enderle, Nélio Schneider e Luciano Cavini Martorano. São Paulo: Boitempo, 2007. p. 29-78.

MELO, Francisco Egberto. A cultura cívica na educação cearense (1963-1973) - na tapeçaria da História, entre o "Livro da Professora" e os festejos à Pátria e ao Progresso. 2006. Dissertação (Mestrado em História Social) - Universidade Federal do Ceará, Fortaleza, CE, 2006.

NUNES, Nataly. Os processos de moralização na escola pública brasileira: estudo das disciplinas de Educação Moral e Cívica e de Ensino Religioso. 2011. Dissertação (Mestrado em Ciências Sociais) - Curso de Pós-Graduação em Ciências Sociais da Universidade Estadual de Londrina, Londrina, PR, 2011.

INFORMATIVO do Deputado Distrital Raimundo Ribeiro. Brasília, Edição I, ano IV, jan./ fev. 2018.

ROSA, Russel Teresinha Dutra. Direito à educação democrática: conquistas legais e ameaças. In: PENNA, Fernando; QUEIROZ, Felipe; FRIGOTTO, Gaudêncio (Org.). Educação democrática: antídoto ao Escola sem Partido. Rio de Janeiro: Uerj, LPP, 2018. p. 51-74.

SANTOS, Patrícia Batista. "Amai a Pátria": o ensino da disciplina escolar educação moral e cívica no Atheneu Sergipense (década de 70 do século XX). 2012. Dissertação (Mestrado em Educação) - Universidade Federal de Sergipe, São Cristóvão, SE, 2012.

SAVIANI, D. A crise política no Brasil, o golpe e o papel da educação na resistência e na transformação. In: LUCENA, Carlos; PREVITALI, Fabiane Santana; LUCENA, Lurdes. A crise da democracia brasileira. Uberlândia: Editora Navegando, 2017.

\section{Sobre as autoras:}

Maria Carolina Miesse: Mestranda em Educação pelo Programa de PósGraduação da Universidade Estadual de Maringá. Bolsista da Capes. E-mail: mariamiesse@hotmail.com, Orcid: https://orcid.org/0000-0002-9694-7009 
Jani Alves da Silva Moreira: Pós-doutora na Universidade Federal do Paraná (UFPR), com estágio pós-doutoral no Programa de Pós-Graduação em Educação da Faculdade de Educação da Universidade de Salamanca (Usal), na Espanha. Doutorado e mestrado em Educação pela Universidade Estadual de Maringá (UEM), com estágio de doutoramento-sanduíche apoiado pela Capes/PSDE, no Instituto de Educação da Universidade de Lisboa (ULisboa). Graduação em Pedagogia pela UEM. Líder do Grupo de Estudos e Pesquisa em Políticas Educacionais, Gestão e Financiamento da Educação (Gepefi/CNPq), professora adjunta do Departamento de Teoria e Prática da Educação (DTP/UEM) e do Programa de Pós-Graduação em Educação (PPE/UEM), na linha de Política e Gestão em Educação. Tem experiência na área de Educação, com ênfase nos temas Políticas para o Financiamento e Gestão da Educação; Políticas Educacionais e a Influência dos Organismos Internacionais; Políticas Educacionais e a Relação Público-Privada; Políticas para Valorização e Formação de Professores; e Políticas Públicas e Gestão Educacional no Brasil. E-mail: professorajani@hotmail.com, Orcid: https://orcid. org/0000-0002-3008-0887

Vânia de Fátima Matias de Souza: Doutora em Educação pela Universidade Estadual de Maringá. Docente adjunta do Departamento de Educação Física e do Programa de Pós-Graduação em Educação da Universidade Estadual de Maringá (UEM). E-mail: vfmatias@gmail.com, Orcid: https://orcid.org/0000-0003-4631-1245

\section{Recebido em: 23 de abril de 2020}

Aprovado em: 28 de julho de 2020 
